\title{
Analysis of the E-commerce website-Lianliangou
}

\author{
Wenrong JIANG ${ }^{1, a}$ \\ ${ }^{1}$ The school of computer and information, Shanghai second polytechnic University, Shanghai, \\ 20,China \\ aemail: wrjiang@sspu.edu.cn
}

Keywords: E-commerce website, Lianliangou website, Case analysis, SWOT, SEO

\begin{abstract}
This paper mainly linked Lianliangou website as a case, simply introduces Lianliangou website platform and its subordinate Hangzhou huantuo Trading Co. Ltd, to the actual data, analyzes the operation model, profit model, Lianliangou website marketing strategy, management pattern, and on the basis of these, coupled with the use of SWOT analysis. Analyzed the advantages and disadvantages of Lianliangou website platform. According to these disadvantages, then analysis and put forward some experience and lessons and need to be absorbed by the policy, the company measures improved and even laws and regulations.
\end{abstract}

\section{Introduction}

\subsection{Lianliangou introduction}

Lianliangou is women's Hangzhou huantuo an online shopping platform Trading Co. Ltd which is mainly engaged in men's clothing, men and women, down jacket, sweaters and other clothing wholesale and retail, incorporated in January 29, 2010, with registered capital of 100000 yuan is a regular fashion agents, have Hengyuanxiang, proxy Septwolves brand the. Lianliangou and also use relatively new B2B2C2C mode, dig out the unlimited business opportunities, highlighted the "association" and "cheap" users can purchase price is cheap, and good quality clothing.

\subsection{Operation mode}

Lianliangoud by B2B2C2C mode, simple is the combined low-cost purchase manufacturers large first and the line of cooperation, manufacturers as the first supplier, make profits, with the help of his commodity promotion platform and sell, this is the B2B link, and then purchase Lian Lian as the second suppliers, then supply to small vendors the number of online and offline or online, using the traditional B2C model, by the combination of low-cost purchase to developing operating plans, here is a ring of $\mathrm{B} 2 \mathrm{C}$, and the last of these small vendors or personal opened the shop will be selling to the real consumers, to meet the various needs of consumers. In a certain sense Lianliangou is composed of two sets of B2B2C model.

\subsection{Profit model}

As a B2B2C2C trading platform, Lianliangou is to obtain appropriate benefits through the linkage of each link, line manufacturers Rangli promotion, online sales, win-win strategy can let more and more lines of large manufacturers as a level of suppliers to join the big family of Lianliangou, also can to attract more and more Taobao sellers, offline sellers to wholesale procurement, Lianliangou as a link, to profit from achieve win-win situation. Increase brand promotion and seller line, can let more consumers aware of Lianliangou occurs, brand effect, the advertising revenue can achieve profitability. This is the combined low-cost buy fresh profit model.

\subsection{Marketing strategy}

Lianliangou also has the original marketing strategy, manufacturers in the get below the line after delivery, the depth of investigation of the market, so as to formulate a weekly new special section, low special section to provide authoritative product pictures and authentic products paper description provide Taobao sellers or line of small sellers, help them making operation planning and using fast logistics and put the goods delivered to consumers, and they are able to benefit from it. 


\subsection{The analysis of domestic and foreign}

In recent years, B2B, B2C and C2C occupy the mainstream mode of electronic commerce. However, with the passage of time, some models are not widely recognized and accepted, some models conform to the trend of the times changed slowly, generating a lot of new e-commerce model, such as P2P, O2O etc.. B2B2C is the very mainstream and popular mode of electronic business affairs, after long-term domestic and foreign research, practice, found that different e-commerce models have their respective characteristics.

B2B is the business model for enterprise, is the enterprise and the enterprise marketing relationship, is what we often say that the enterprise procurement, customer population will be relatively small, but the procurement volume will be great. The company will because granting employee benefits or is wholesale and retail for B2B bulk purchase of enterprises, with more affordable prices to meet the needs of large purchase quantity. Current large shopping sites like Jingdong, excellence, No. 1 stores all have their own B2B platform

B2C is the business model for the customer, the same line shopping, is the business to sell goods directly to consumers, but is through the Internet mode, this also is one of the most traditional mode of online shopping. Consumers will place an order and online payment on the Internet to choose goods directly to consumers, businesses from their own warehouse. The credibility of this class of businesses usually have higher visibility and. This mode is also very large consumer groups. Like Jingdong, Amazon, Dangdang, every guest has its own B2C mall.

C2C mode is customer oriented customer, E-bay and the like USA China Taobao is pure B2B mode, the ordinary people can own in the online shop to sell goods, this kind of commodity prices generally relatively low, but the store reputation and product quality can not be guaranteed in real time, and logistics need to the stores of their own control. But the C2C patterns of diversity and flexibility or occupy a space for one person to let him in on the market today.

However, the B2B2C model is the most popular in the current mode of electronic business affairs, Tmall mall is the most classic is the most the most successful B2B2C mall, choose suitable businesses, and verification and validation, to their qualifications through, pass for businessmen in Tmall shopping malls, let they open their own shop in Tmall platform, and to the buyer directly from their own warehouse. Lianliangou is built on the basis of B2B2C model, this business model is very flexible, has the very good prospects for development. The wholesale and retail channels to sell down jacket, sweaters can acquire great wealth. Buyers and sellers can make big concessions and benefits from. development.

\section{SWOT analysis of Lianliangou website}

\subsection{Advantages analysis}

(1)Lianliangou as a line level agents from large manufacturers line directly getting goods manufacturers to make the appropriate allowing more profits, has the absolute price advantage. With the support of an agent's line, Lianliangou can get sufficient inventory to meet the needs of buyers. This is the joint of low-cost goods advantage, compared with other businesses, no prices high and difficult to purchase troubled.

(2)Lianliangou have their own homepage, real-time updates through the website content, the promotion of weekly different activities, so that buyers can be more intuitive to see the commodity information, make platform become a brand promotion propaganda, can attract more line manufacturers to cooperate with it, give full play to Lianliangou brand advantage. 


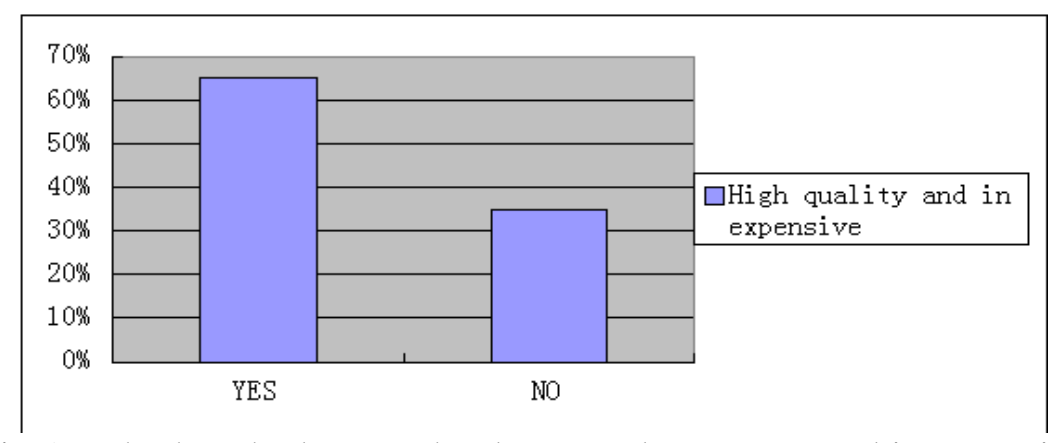

Fig.1. Whether the buyers that buy goods Wumart and inexpensive

(3)Lianliangou has seven wolves and Heng Yuan Xiang and other big brands, these brands are well known to have certain persuasion, have a good reputation, but also to attract more consumers to buy the honest. As the platform for the managers do not need to put too much energy and time for the promotion of the goods. The company should according to the characteristics of the same type, and competition from other sites.

\subsection{Disadvantages analysis}

(1)Lianliangou lack adequate customer service, butt home manufacturers and the need for docking small buyers home two sets of lineup to meet customer demand for both buyers and sellers, an e-commerce platform, need good pre-sales services, sale of services, and after sale service, because low-cost purchase no good the customer service team, customers may be feedback to the relatively poor user experience, and thus no longer to buy. Lead to the loss of customers.

(2)In logistics, Lianliangou as a network of wholesale and retail agents, the need for large quantities of goods distribution, although some customers can come from the warehouse to mention, but for those relatively remote client, the whole process of logistics or take big risks. There are likely to be the problem of packet loss, damaged goods, the seller and the buyer will need to bear some of the losses, it is after sale service support raised a lot of problems. The logistics of the weaknesses will also lead to the loss of customers.

(3) Although Lianliangoud a commercial advantage, but it is only so few, the category and quantity of commodities diversity or have limitations, some want to buy a particular brand down buyers may suit doesn't pick their favorite goods in the shop, so as to give up purchasing.

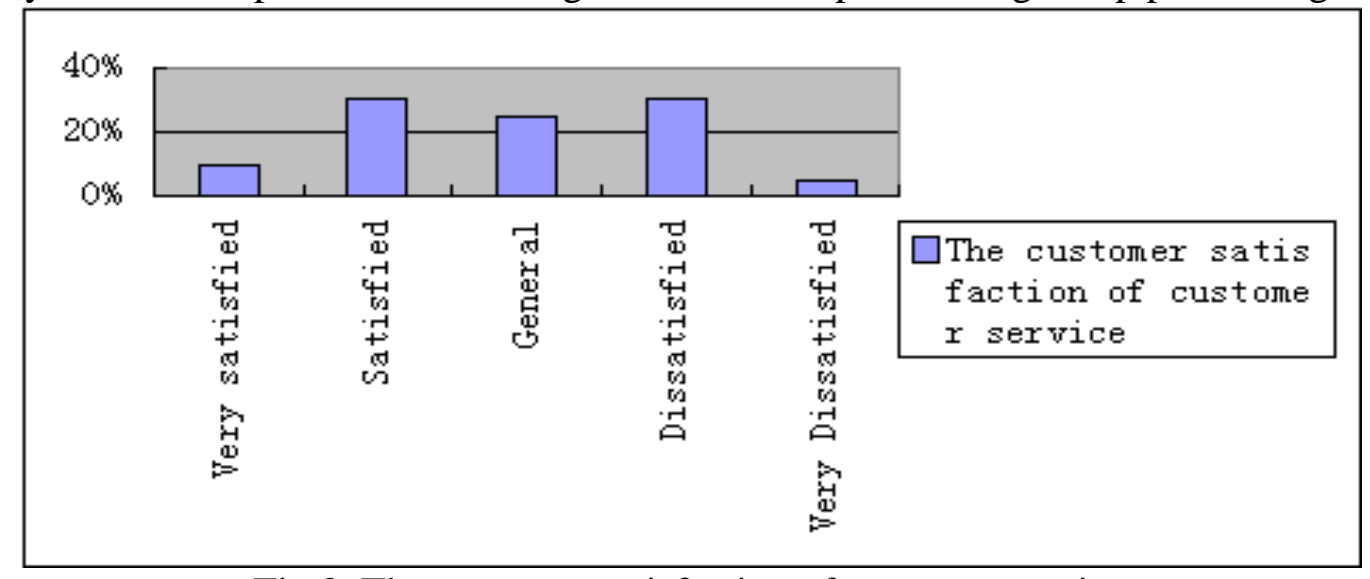

Fig.2. The customer satisfaction of customer service

\section{Improvement measures and feasibility}

\subsection{Improve popularity}

Lian Lian buy want a foothold in the market also need to improve the popularity of the site, in order to improve the site popularity, in the Internet can participate in the search engine rankings, enhance their own specific keyword in the search results ranking, also can exchange links with other major portals to improve their flow, can also be set in advertising specific plate to attract more businesses to the eyes. To bring more visitors. But the online market, can go to shopping malls in 
the booth setup, promotional activities under the line, do communicate with more suppliers, also can go to the community, to do publicity to the ordinary people, let them know that Lian Lian purchasing advantages, promotion platform influence.

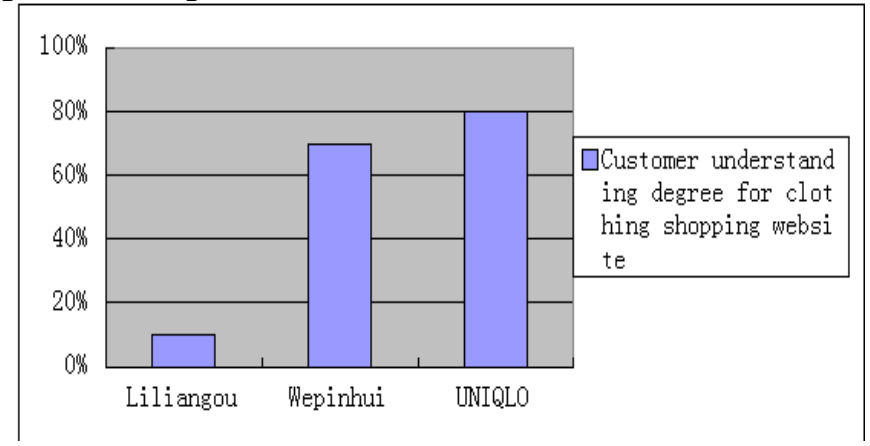

Fig.3. Customer understanding degree for clothing shopping website

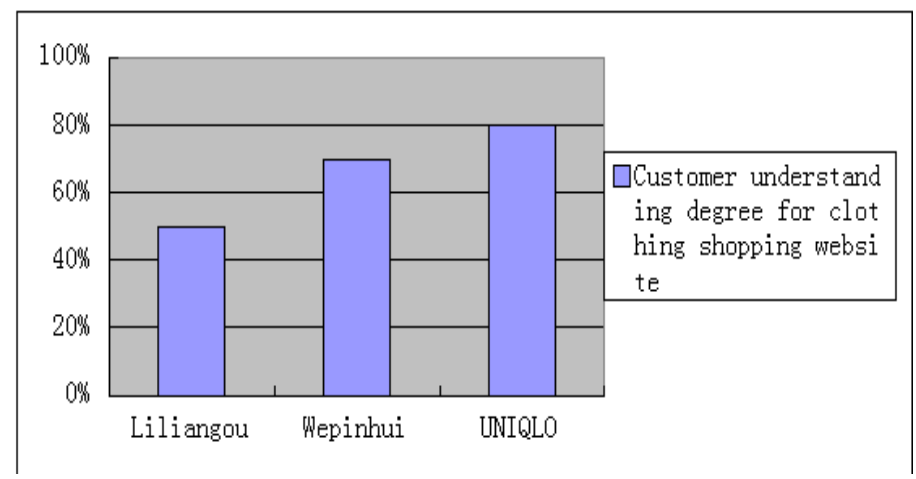

Fig.4. Customer understanding degree for clothing shopping website after change

Feasibility: Double push the line takes a lot of manpower and material resources and financial resources, but also need a good operation team to support, but the popularity of the website is very important for the classification of information platform, improvement measures mentioned above is effective, face-to-face propaganda can bring great harvest, but also should be according to the actual situation of quasi, make some adjustment and sacrifice can play the feasibility of the scheme.

\subsection{Improve customer service}

In customer service, the website can be set up to formulate the special customer service department, equipped with the personnel of the service customer customer service problems specially treated, and do well the service pre-sale and sale, to the seller and the buyer communication without obstacles, so as to reduce the loss as much as possible, cause unnecessary trouble, a good customer service team to let both sides mutual win, to retain loyal customers, resulting in subsequentpurchasebehavior.

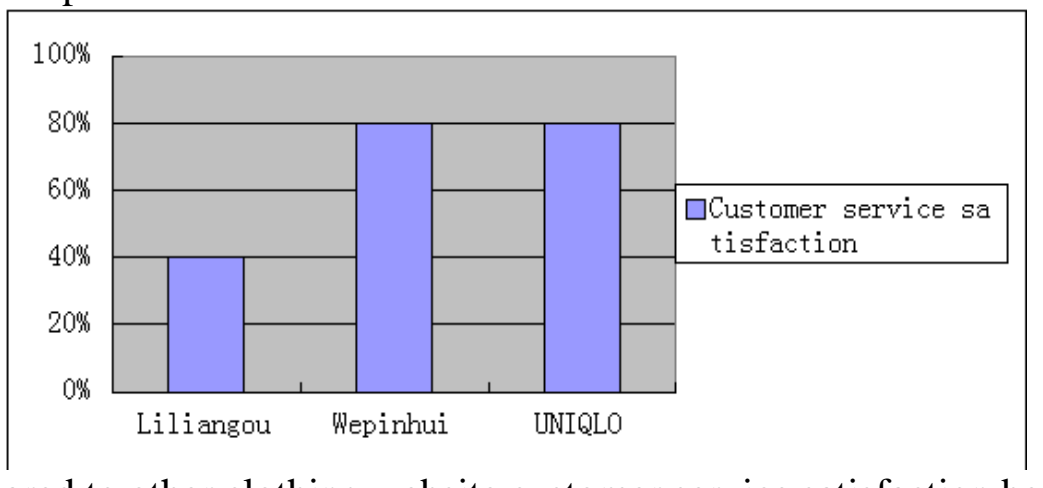

Fig.5. Compared to other clothing website customer service satisfaction before change 


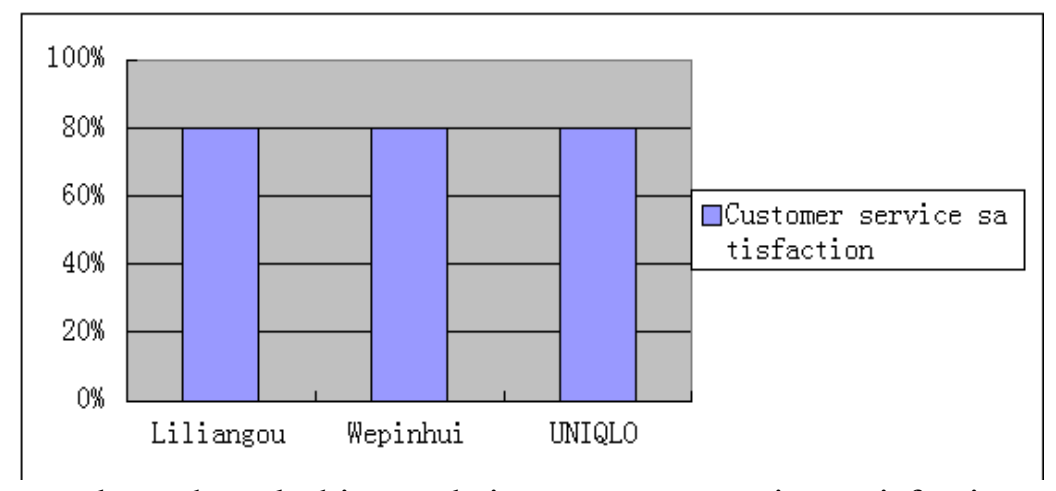

Fig.6. Compared to other clothing website customer service satisfaction after change

Feasibility: Customer service is a service is the core in the process of online shopping, online shopping is very important for the process, in order to enhance customer service team can recruit some appropriate customer service personnel in the society and training. This approach the rewards far exceed the expenditure. Therefore, I think that the feasibility of this scheme has high.

\subsection{Improve the logistics}

In logistics, the logistics can be contracted to third party, let the third party self distribution, charge a cost benefit from. This approach can greatly reduce the loss of buyers and sellers, but also can solve the problem caused by the improper communication logistics. Now, the domestic third party logistics have gradually mature, also be the trust and trust. I think a good logistic team to ensure the net buys, is the solid backing, has a very important position. Also has the high feasibility.

\section{Summary}

Hangzhou huantuo trading company under the "Lianliangou" a platform based on B2B2C2C mode of e-commerce platform, Lianliangou makes full use of the powerful Internet, find business opportunities, to open the online market, but also broaden their own line market. Have a charismatic big brands, and the stability of inventory and low prices, because of getting goods directly from manufacturers, the product quality can be ensured, the various advantages to attract more businesses to join the big family of low-cost purchase. However, Lianliangou also exist many problems, such as customer service, logistics, and the diversity of the goods are to be improved. But through the measures effectively targeted to solve these problems, can bring great profits to the company. Customer service, logistics is the priority among priorities in the process of online shopping, through the training of the customer service team, contracted third party logistics, I believe that these problems can be smoothly done or easily solved.The development of electric market change rapidly, I believe that as long as adhere to the "customer first" philosophy, integrity management, to make up for the mistakes and shortcomings, to set up the good brand image in the development at the same time, to meet the market demand, in order to have a bright future.

\section{Acknowledgement}

This work is supported by the Key Disciplines of Computer Science and Technology of Shanghai Polytechnic University under Grant No. XXKZD1604.

\section{References}

[1] Wenrong Jiang, Shiwei Li. Analysis of Xiaomi Tech's E-commerce model[J]. 2nd International conference on E-commerce and Contemporary Economic Development (ECED 2015), Nanjing, China, December 5-6, 2015, DEStech Publications, Inc. 196-200.

[2] Wenrong Jiang, Jian Chen.Analysis of the wabsite-Hj operations[J]. 2015 3nd International Conference on Applied Social Science Research (ICASSR 2015), Limassol, Cyprus, October 4-5, 2015, 103-106. 
[3] Wenrong Jiang, Hao Du. The Investigation and Analysis of Outdoor Advertising Willingness about Different Types of E-commerce[J]. 2014 International Conference on Economy and Society (EAS 2014), Chicago, Illinois, USA, 2014(10) October 24-25, 2014, Research and Applications in Economics, 2014(7), Vol 2, 51-55.

[4] Zhikun Hu, Wenrong Jiang, Cuihong Wu, Hailan Pan, Jian Chen. The Methods and Analytical Studies of Taobao Stores Promotion[J]. The Ninth Wuhan International Conference on E-Business (WHICEB 2010), Wuhan, China: IEEE Press. 2010(5):118-122.

[5] Wenrong Jiang, Shiwei Lin. Information Technology in the E-commerce Marketing Strategy of OAWAY Website[J]. ECWAC 2013, Wuhan, China: Advanced Materials Research (Volumn 859), 2014(1):551-555

[6] Wenrong Jiang, Jiajun Tang. The new exploration of network marketing based on "S.CN" [J]. Int'l Conf. on e-Learning, e-Business, EIS, \& e-Government (EEE'14), CSREA Press, Las Vegas, USA, 2014(7) July 21-24, 2014:107-113.1-60132-268-2

[7] Wenrong Jiang, Shiwei Lin. Information Technology in the E-commerce Marketing Strategy of OAWAY Website[J]. 2013 3rd International Conference on Electronic Commerce 、Web Application and Communication (ECWAC 2013), Wuhan, China: Advanced Materials Research (Volumn 859), 2014(1):551-555. EI: 20140317205070

[8] Wenrong Jiang, Jian Chen, Wei Tao. The Development of Automotive Interior Sales Website[J]. Communications in Computer and Information Science (Volumes 268), 2011(12):342-348. EI:20122015019844 